\title{
Increased Calcineurin A Expression Is Associated with a Lower Relapse-Free Survival Rate after Colorectal Cancer Surgery
}

\author{
Hiroaki Niitsu $^{a}$ Takao Hinoia, e Kazuhiro Sentani $^{b}$ Shoichiro Mukai ${ }^{a}$ b \\ Tomohiro Adachi $^{a}$ Yasufumi Saito ${ }^{a, c}$ Masashi Miguchi ${ }^{a, d}$ Masatoshi Kochi ${ }^{a}$ \\ Haruki Sada ${ }^{a}$ Naohide Oue ${ }^{b}$ Wataru Yasui ${ }^{b}$ Hideki Ohdan $^{a}$ \\ ${ }^{a}$ Department of Gastroenterological and Transplant Surgery, Applied Life Sciences, and ${ }^{b}$ Department of Molecular \\ Pathology, Institute of Biomedical and Health Sciences, Hiroshima University, ' Department of Surgery, Hiroshima \\ General Hospital of West Japan Railway Company, and d Department of Surgery, Hiroshima City Funairi Citizens \\ Hospital, Hiroshima, and e Department of Surgery, Institute for Clinical Research, National Hospital Organization \\ Kure Medical Center and Chu-goku Cancer Center, Kure, Japan
}

\section{Key Words}

Colorectal cancer · Surgery · Calcineurin · Biomarker ·

Relapse-free survival

\begin{abstract}
Objective: Increased expression of calcineurin in colorectal cancer (CRC) has been reported. Although the oncogenic function has been suggested, the clinical relevance is still unclear. We herein studied calcineurin expression as a prognostic biomarker in patients receiving curative surgery for stages I-III CRC. Methods: In 121 patients with stages I-III CRC treated at Hiroshima University between 1997 and 2003, calcineurin A expression was examined using immunohistochemistry $(\mathrm{IHC})$ staining of surgical specimens. Specimens were considered positive for calcineurin A if any IHC-stained cells were observed within the carcinomatous area, and clinicopathological characteristics and survival outcomes were compared between IHC-positive and -negative groups. $\boldsymbol{R e}$ sults: Calcineurin A was preferentially expressed in the cytoplasm of cancer cells, and a median of $8 \%$ of the cells (range:
\end{abstract}

0-80\%; interquartile range: $0-22.5 \%)$ were stained within the carcinomatous areas. Of 121 cases, 81 were determined as IHC positive while 40 were determined to be negative. Positive expression of calcineurin A, as well UICC-TNM stage, was associated with low relapse-free survival (RFS) rates in multivariate analyses (hazard ratio $=2.92 ; 95 \% \mathrm{Cl}: 1.27-7.92$; $p=0.010)$. Conclusion: Increased calcineurin A expression is associated with lower RFS rates and may have clinical value in predicting recurrence.

(c) 2016 S. Karger AG, Basel

\section{Introduction}

Colorectal cancer (CRC) has emerged as the leading cause of death in developed countries, and a number of surgical resections are performed for the treatment of CRC. However, according to the investigation by the Japanese Society for Cancer of Colon and Rectum, $17.3 \%$ of Japanese CRC patients unfortunately experience recurrence even after undergoing curative resections for stages

\section{KARGER}

E-Mail karger@karger.com www.karger.com/pat
(C) 2016 S. Karger AG, Basel

1015-2008/16/0836-0308\$39.50/0
Takao Hinoi

Department of Surgery, Institute for Clinical Research

National Hospital Organization Kure Medical Center and Chu-goku Cancer Center

3-1 Aoyama-cho, Kure City, Hiroshima 737-0023 (Japan)

E-Mail thinoi@ hiroshima-u.ac.jp 
I-III CRC [1]. Surveillance and/or adjuvant chemotherapy after curative surgery are determined on the basis of the conventionally used Duke's classification $[2,3]$ or more recently the UICC-TNM staging system (Union for International Cancer Control, 7th edition) [4], which are precise predictors of the prognosis of CRC [5]. Moreover, other predictors, including poor differentiated histology $[5,6]$, preoperative carcinoembryonic antigen (CEA) level elevation [5], blood or lymphatic vessels invasion [5], inadequate sampled lymph nodes $[5,7,8]$, and perineural invasion [9], have been reported as useful. Most recently, with the development in molecular cancer biology, various new candidate molecules have been investigated as potential biomarkers for prediction of recurrence or prognosis [10-17]. Moreover, protein expression profiling using antibody microarray has also been previously reported in order to identify the candidates for novel biomarkers of CRC, and 25 proteins which are preferentially expressed in human CRC have been identified out of 224 proteins contained in the antibody microarray. Subsequently, 7 novel proteins including cytokeratin 13, calcineurin, CHK1, clathrin light chain, MAPK3, phosphorPTK2/focal adhesion kinase, and MDM2 were reported as new potential markers after validating immunohistochemistry and immunoblotting analyses using surgical specimens [18].

Of these candidates for novel biomarkers, calcineurin is a $\mathrm{Ca}^{2+}$ - and calmodulin-dependent serine/threonine protein phosphatase [19-21] that is composed of the catalytic subunit calcineurin $\mathrm{A}$ and $\mathrm{Ca}^{2+}$-binding subunit calcineurin $B$ as a heterodimer $[20,21]$. Calcineurin dephosphorylates the nuclear factor of activated T-cell (NFAT), and subsequently NFAT is translocated into the nucleus and acts as a transcriptional factor that promotes various cellular activities [22-24]. For CRC, it has been reported that cycolooxgenase-2 (COX-2, a known oncogene for $\mathrm{CRC}$ ) expression and prostaglandin $\mathrm{E}_{2}$ production were induced with the pharmacological stimuli of the $\mathrm{Ca}^{2+}$-calcineurin-NFAT signaling pathway [25] and that expression of calcineurin A was specifically increased in human CRC, resulting in activation of phosphatase activity of calcineurin [26]. Moreover, regarding other malignancies, there have been some previous reports describing that the $\mathrm{Ca}^{2+}$-calcineurin-NFAT signaling pathway enhances the transcriptional activity of oncogenes, including c-myc, COX-2, STAT3, heat shock protein 27, and DJ-1 [27-29], increases cancer cell proliferation in pancreatic cancer [27] and hepatocellular carcinoma [29], and promotes tumorigenesis in prostate cancer [30]. Although these reports suggest the oncogenic function of calcineurin, little is known that is clinically relevant. We herein investigated the correlation between the expression of calcineurin A and the prognosis after curative surgery for CRC to determine the clinical value as a prognostic biomarker.

\section{Materials and Methods}

Patients

We retrospectively investigated the details of 121 patients who had stages I-III CRC according to the UICC-TNM classification [4] and had undergone curative resection at Hiroshima University Hospital between 1997 and 2003. For immunohistochemistry (IHC) analyses, archived formalin-fixed paraffin-embedded samples from these patients were used. Identifying information from all samples was removed before the analysis for strict privacy protection. This procedure was performed in accordance with the Ethical Guidelines for Human Genome/Gen Research enacted by the Japanese Government, and this study was performed with permission of the Ethics Committee of Hiroshima University.

\section{Immunohistochemistry}

A Dako LSAB Kit was used for IHC analysis. In brief, sections were subjected to microwave pretreatment in citrate buffer for 15 min to retrieve antigenicity. After peroxidase activity was blocked with $3 \% \mathrm{H}_{2} \mathrm{O}_{2}$-methanol for $10 \mathrm{~min}$, sections were incubated with normal goat serum (Dako) for 20 min to block nonspecific antibody-binding sites. Sections were incubated with the following primary antibodies: anti-calcineurin A (diluted 1:1,000, clone CNA1; Sigma-Aldrich) and anti-calcineurin B (1:3,000, clone CN-B1; Sigma-Aldrich). Sections were incubated with primary antibody for $1 \mathrm{~h}$ at $25^{\circ} \mathrm{C}$, followed by incubations with peroxidase-labeled anti-mouse IgG for $60 \mathrm{~min}$. Staining was completed with a 10-min incubation with the substrate-chromogen solution. The sections were counterstained with $0.1 \%$ hematoxylin.

\section{Evaluation of IHC Analyses of Calcineurin A}

Immunoreactivity in the carcinomatous area was evaluated and compared to the those in normal colonic epithelium as negative internal controls; specimens were considered as IHC positive if any IHC-stained cells were present within the carcinomatous area. Moreover, the percentage of stained cells within the carcinomatous area was also studied. Results of IHC were evaluated by two independent investigators (K.S. and W.Y.), and disagreement was resolved by review and discussion between the investigators.

\section{Statistical Analyses}

The following characteristics were compared between the groups with and without expression of calcineurin A in IHC (IHCpositive and IHC-negative groups, respectively): age, sex, tumor location, histologic type, invasion depth and nodal metastasis classified according to the UICC-TNM classification, vascular and lymphatic involvement, and levels of the tumor markers CEA and carbohydrate antigen 19-9 (CA19-9). The results are reported as medians and ranges for quantitative variables and as frequencies for categorical variables. Comparisons were conducted using Wilcoxon's rank-sum tests for quantitative variables and Pearson's $\chi^{2}$ test for categorical variables. 

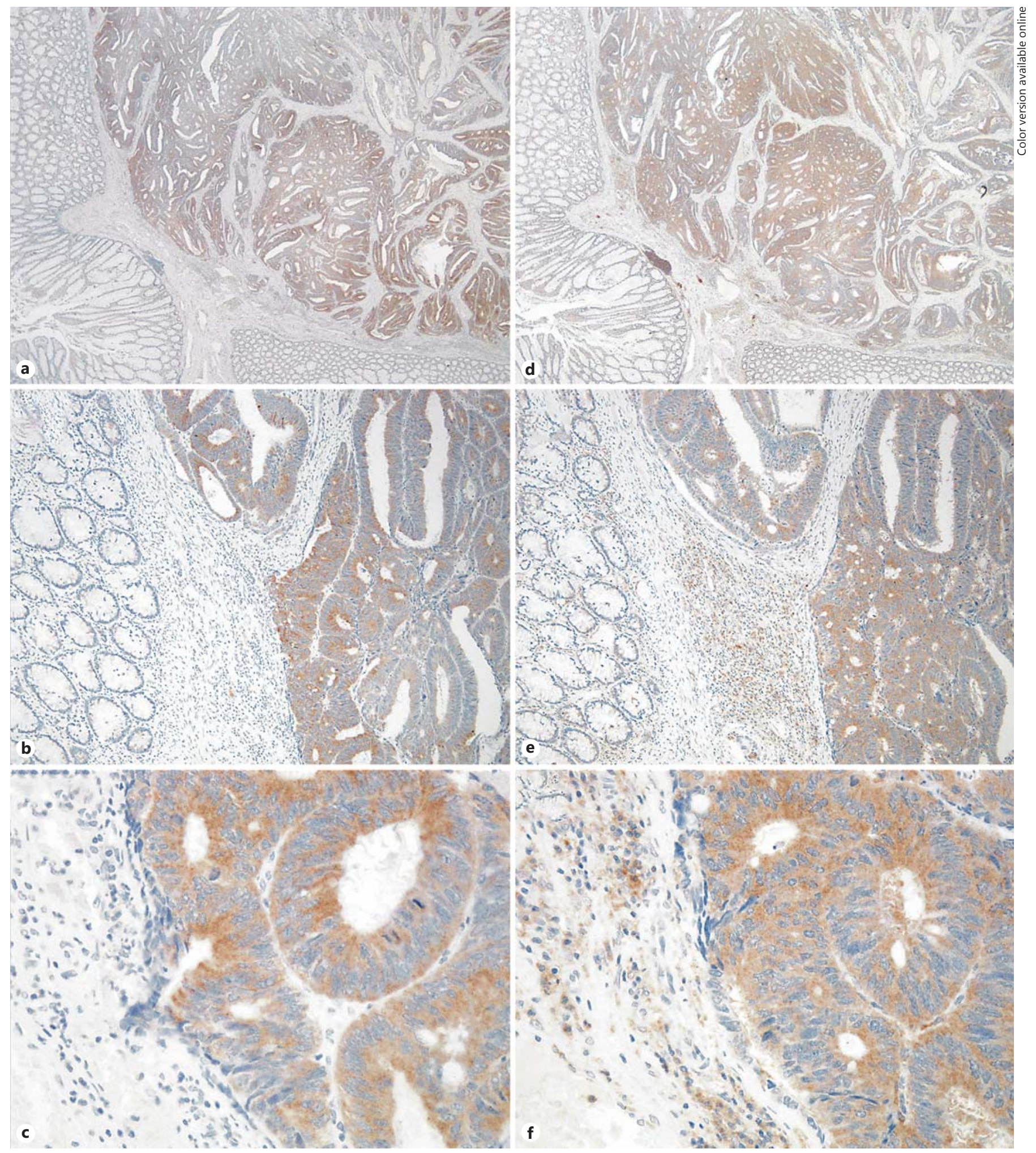

Fig. 1. Representative picture of IHC of calcineurin A (a-c, magnification $\times 40, \times 100$, and $\times 400$, respectively) and calcineurin B (d-f, magnification $\times 40, \times 100$, and $\times 400$, respectively) in serial sections from surgical specimens of human CRC. Normal colonic epithelium is included at the left part of each picture, and carcinoma is at the right part of each picture. 
Survival outcomes were compared between IHC-positive and IHC-negative groups for calcineurin A by using log-rank tests and were summarized as Kaplan-Meier curves and hazards ratios (HRs) with 95\% CI. We separately analyzed overall survival (OS) and relapse-free survival (RFS) rates with the events for each type of survival being defined as all-cause death and death or relapse, respectively. Subsequently, multivariate analyses for OS and RFS were conducted using Cox proportional hazard models, including variables at $\mathrm{p}<0.05$ in the log-rank tests. The results of these univariate or multivariate analyses were presented as $\mathrm{HR}$ and 95\% CI with the corresponding $\mathrm{p}$ value.

All statistical analyses were performed using JMP 10 software (SAS Institute, Cary, N.C., USA).

\section{Results}

In IHC analyses, calcineurin A was preferentially expressed in the cytoplasm of adenocarcinomas, and calcineurin B was also expressed in the cytoplasm of adenocarcinoma colocalized with calcineurin A (fig. 1). A median of $8 \%$ of the cells (range: $0-80 \%$, interquartile range: $0-22.5 \%$ ) were stained with calcineurin $\mathrm{A}$ in the carcinomatous areas, and 81 of 121 patients' specimens were determined as IHC positive while 40 were determined to be negative (table 1 ).

There were no statistically significant differences in the clinicopathological parameters between the two groups, except for higher frequencies of poorly and mucinous-differentiated histologic type in the IHC-negative group (table 1).

In the survival analyses using log-rank tests, longer RFS rates were observed in the IHC-positive group than in the IHC-negative group, while there was no significant difference in the OS rate between the two groups (fig. 2). Subsequently, the correlation between RFS and calcineurin A expression in IHC was studied in the multivariate analyses, and the positive expression of calcineurin $\mathrm{A}$ in IHC as well as UICC-TNM stage were determined as significant risk factors for lower RFS rates (table 2). Furthermore, we estimated the impact of calcineurin expression in IHC on RFS by each UICC-TNM stage; RFS rates were significantly different among patients with stage III CRC (fig. 3).

\section{Discussion}

Although a higher expression of calcineurin A in CRC than in normal colonic epithelium has been reported previously $[18,26]$, the intensity and/or frequency of calcineurin A expression in CRC had not been reported. In the
Table 1. Comparisons of clinicopathological parameters between the positive and negative expression of calcineurin A

\begin{tabular}{|c|c|c|c|}
\hline & \multicolumn{2}{|c|}{ Calcineurin A IHC } & \multirow[t]{2}{*}{$\mathrm{p}$} \\
\hline & $\begin{array}{l}\text { negative } \\
(\mathrm{n}=41)\end{array}$ & $\begin{array}{l}\text { positive } \\
(\mathrm{n}=80)\end{array}$ & \\
\hline \multicolumn{4}{|l|}{ Age, years } \\
\hline Median (range) & $61(29-89)$ & $65.5(36-86)$ & 0.261 \\
\hline$<65$ & 24 & 37 & 0.250 \\
\hline$\geq 65$ & 17 & 43 & \\
\hline \multicolumn{4}{|l|}{ Sex } \\
\hline Male & 16 & 31 & 1.00 \\
\hline Female & 25 & 49 & \\
\hline \multicolumn{4}{|l|}{ Tumor location } \\
\hline Right colon & 6 & 16 & 0.535 \\
\hline Left colon & 18 & 28 & \\
\hline Rectum & 17 & 36 & \\
\hline \multicolumn{4}{|l|}{ Histologic type } \\
\hline Well/moderately & 37 & 79 & 0.045 \\
\hline Poorly/mucinous & 4 & 1 & \\
\hline \multicolumn{4}{|l|}{ Invasion depth } \\
\hline Tis/T1 & 8 & 11 & 0.838 \\
\hline $\mathrm{T} 2$ & 10 & 20 & \\
\hline $\mathrm{T} 3$ & 17 & 34 & \\
\hline $\mathrm{T} 4$ & 6 & 15 & \\
\hline \multicolumn{4}{|l|}{ Nodal metastasis } \\
\hline Absent & 26 & 53 & 0.841 \\
\hline Present & 15 & 27 & \\
\hline \multicolumn{4}{|c|}{ Nodal metastasis (stage III), n } \\
\hline Median (range) & $3(1-9)$ & $2(1-13)$ & 0.133 \\
\hline \multicolumn{4}{|l|}{ Vascular invasion } \\
\hline Absent & 15 & 25 & 0.683 \\
\hline Present & 26 & 55 & \\
\hline \multicolumn{4}{|l|}{ Lymphatic invasion } \\
\hline Absent & 6 & 9 & 0.575 \\
\hline Present & 35 & 71 & \\
\hline \multicolumn{4}{|l|}{ Stage } \\
\hline I & 14 & 28 & 0.950 \\
\hline II & 12 & 25 & \\
\hline III & 15 & 27 & \\
\hline \multicolumn{4}{|l|}{ CEA } \\
\hline Median (range) & $4.2(0.6-84.9)$ & $3.85(0.6-381)$ & 0.985 \\
\hline$\geq 5.1$ & 16 & 29 & 0.843 \\
\hline \multicolumn{4}{|l|}{ CA19-9 } \\
\hline Median (range) & $16(0-180)$ & $13(0-138)$ & 0.143 \\
\hline$\geq 38$ & 3 & 9 & 0.749 \\
\hline \multicolumn{4}{|c|}{ Adjuvant chemotherapy } \\
\hline Overall & 19 & 36 & 1.00 \\
\hline Stage II $(\mathrm{n}=37)$ & 6 & 17 & 0.470 \\
\hline Stage III $(\mathrm{n}=42)$ & 13 & 18 & 0.273 \\
\hline
\end{tabular}

current study of the 121 CRC patients, it was found that the immunoreactivity of IHC for calcineurin A varies from specimen to specimen. However, this diversity of expression level would give rise to some arguments for a 


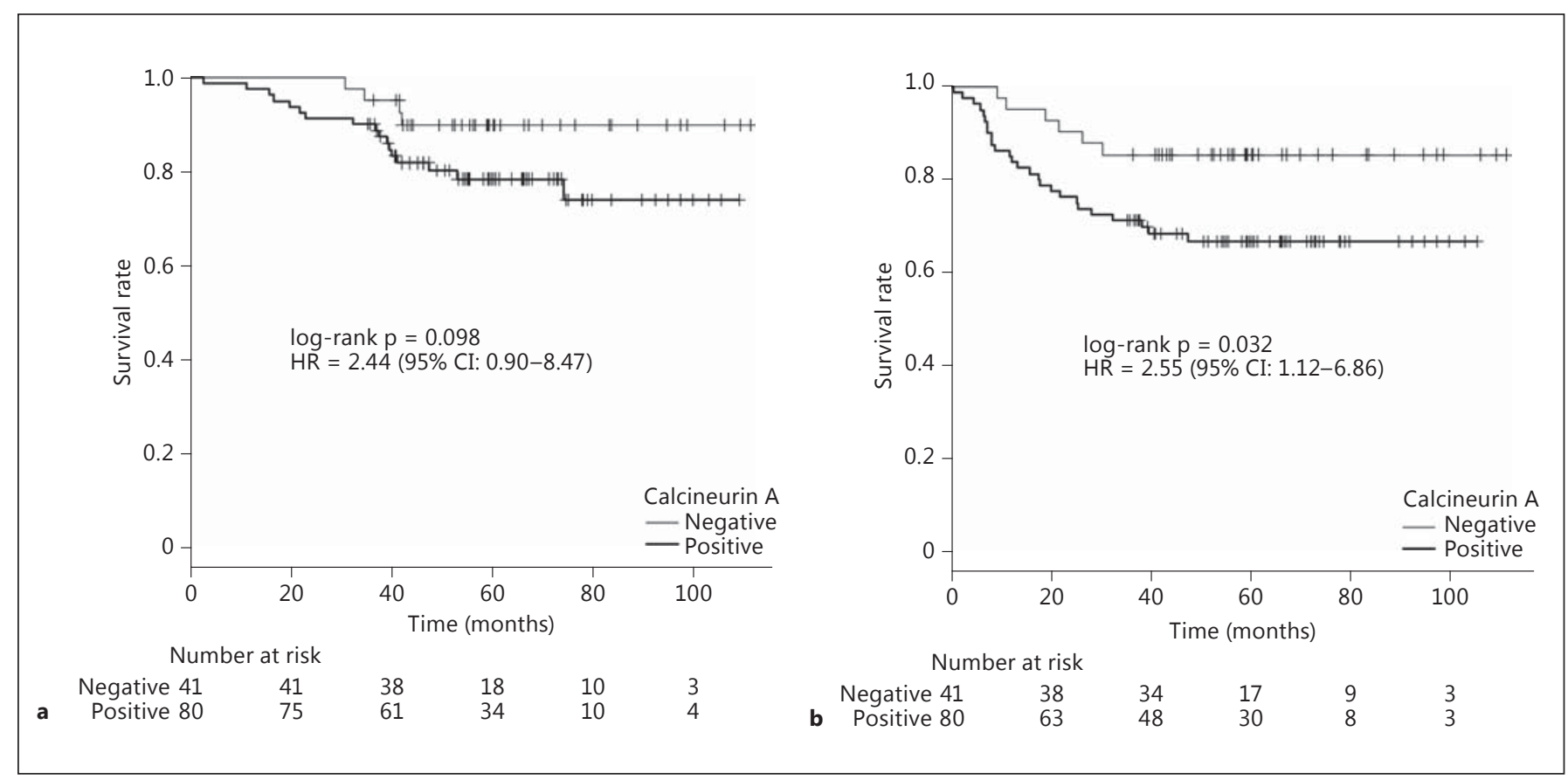

Fig. 2. Survival analyses between the calcineurin A-positive and calcineurin A-negative groups: OS (a), RFS (b).

cutoff value when we classify the expression of calcineurin A to be higher or not. In the current study, we evaluated the expression in accordance of whether any IHCstained cells were present or not within the carcinomatous area because the criteria were thought to be valid for the following two reasons. First, the number of cases assigned to each group was balanced; one-third of all studied specimens were determined as IHC negative and the rest as IHC positive. Second, interobserver reproducibility might be reduced. The evaluations whether calcineurin A was positive or negative made by the two independent investigators (both were certificated pathologists) were all identical, whereas there were some disagreements for scoring of the IHC-positive percentage. There is no doubt that the biological significance between IHCnegative and slightly positive specimens such as the presence of $1 \%$ stained cells within the carcinomatous area might be an important issue and that a better cutoff value should be optimized in future large-scale studies; however, the criteria for the evaluation of IHC specimens in the current study seemed sufficient to investigate the prognostic value of calcineurin A expression in IHC.

Under these simple criteria of IHC for calcineurin A, it was demonstrated that the positive expression of calcineurin A in IHC had a prognostic biomarker in terms of
RFS, independent from UICC-TNM stage. To interpret the results of study, the impact of adjuvant chemotherapy should be taken into consideration. In the current study, the performance rate of adjuvant chemotherapy in stages II and III was not significantly different between the IHCpositive and -negative groups. Moreover, there were no differences in survival outcome with or without the performance of adjuvant chemotherapy in stages II and III disease (corresponding $\mathrm{p}$ values of log-rank tests were 0.263 and 0.161 , respectively) in our cohorts. Therefore, although there is no doubt of the clinical value of adjuvant chemotherapy, it seemed, at least in our study cohort, not to influence the result focused on the prognostic value of positive IHC for calcineurin $\mathrm{A}$. On the other hand, although adjuvant chemotherapy of a 5-FU-based regimen was performed in some of the cases in the current study, the RFS rates in the IHC-positive group were significantly lower in stage III disease (fig. 3). Moreover, in stage II disease, the RFS rates in the IHC-positive group were not statistically different but seemed lower. Based on this result it might be a new strategy that more intensive but toxic regimens, including FOLFOX or CapeOX, which have the best evidence of survival benefit for adjuvant chemotherapy [31], be applied to stage II or III disease with positive expression of calcineurin A in IHC. This 
Table 2. Univariate and multivariate analyses for RFS

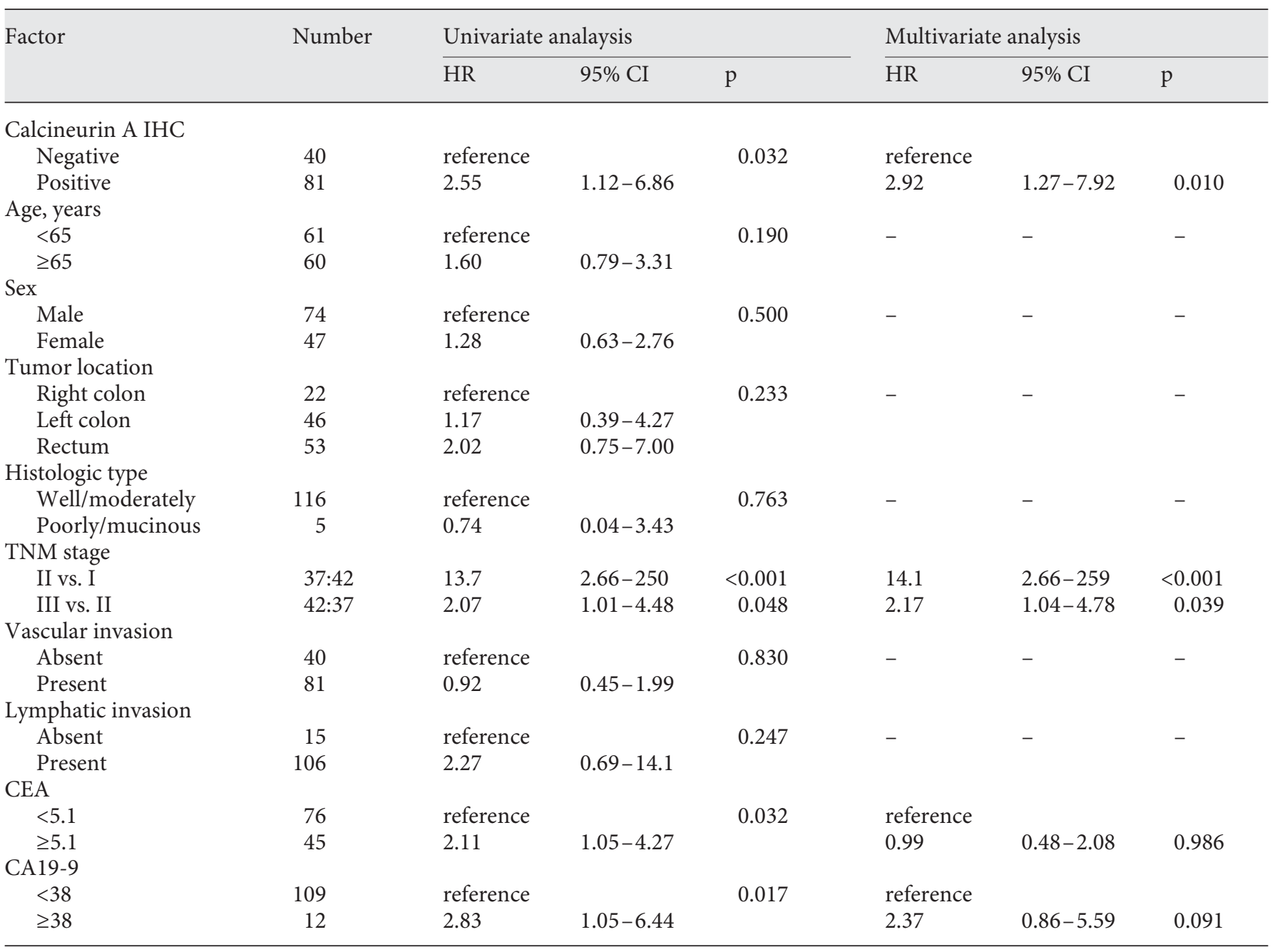

new strategy should be studied in the future investigations.

More interestingly, calcineurin inhibitors such as cyclosporine and tacrolimus can be used for the treatment of patients with higher calcineurin expression as an adjuvant or recurrent therapy. While in vitro treatment of cyclosporine has been reported to inhibit proliferation of colon cancer cell lines (HT29 and WiDr) [32], cyclosporine can also inhibit T-cell activity in vivo and may increase the development of cancer or secondary carcinogenesis [33-35]. Furthermore, there are some agents that can act as immunosuppressants and chemotherapeutic drugs, including cyclophosphamide, methotrexate, and evelorimus. These agents act as immunosuppressants in lower doses, while they act as anticancer drugs in higher doses, and therefore dosage of calcineurin inhibitors against CRC might be important. Further experiments in animal models may be required to determine the effect on both CRC and immunology when administering calcineurin inhibitors in various dosages.

This study has some limitations. First, although this study showed IHC positivity for calcineurin A was significantly associated with a lower RFS rate, this is a singleinstitute small-sized study. To verify the reliability of this result, a large and multicenter prospective study may be required, and prospective observational studies are being conducted. Second, the expression of calcineurin seemed to have no impact on OS rate in this study. However, a possible explanation underlying this finding is few events for OS, resulting in a low statistical power. More specifi- 


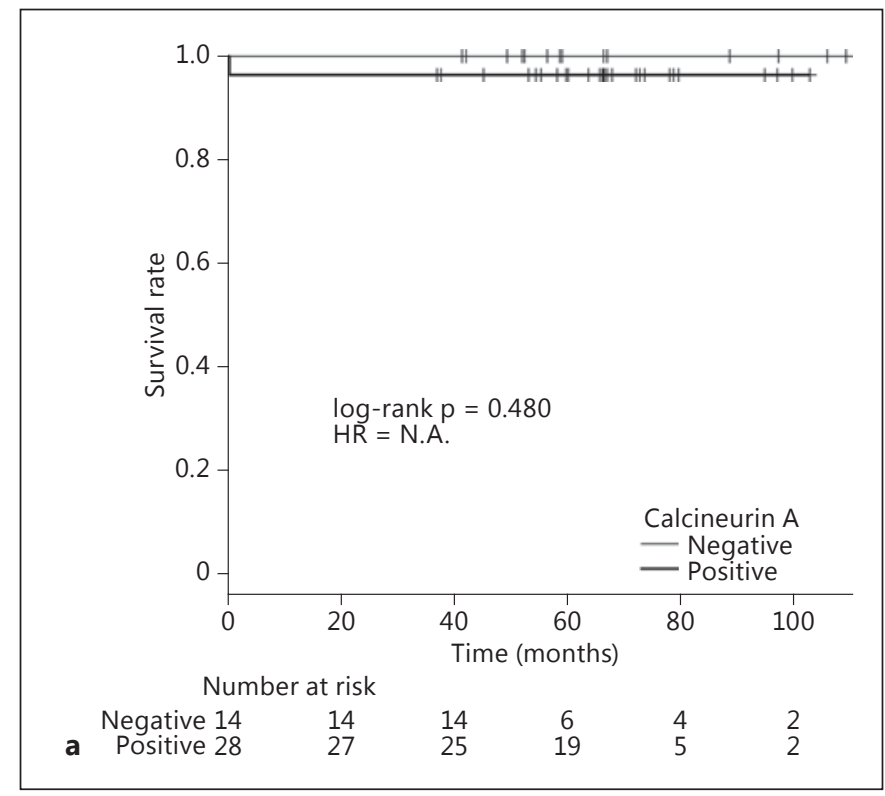

Fig. 3. RFS rates between the calcineurin A-positive and calcineurin A-negative groups in stages I, II, and III CRC (a-c, respectively).

cally, if recurrence after curative resection occurred, it is not directly associated with death because some recurrent tumors were resectable, thus prolonging OS in such cases. Therefore, a future study with a larger sample size may be required to determine the significance in OS.

In conclusion, the expression of calcineurin A in IHC has clinical value to predict a lower RFS rate after curative resection of stages I-III CRC. Based on the result of the study, a new strategy should be established for surveillance and/or adjuvant chemotherapy after curative surgery for $\mathrm{CRC}$ in the future trials.
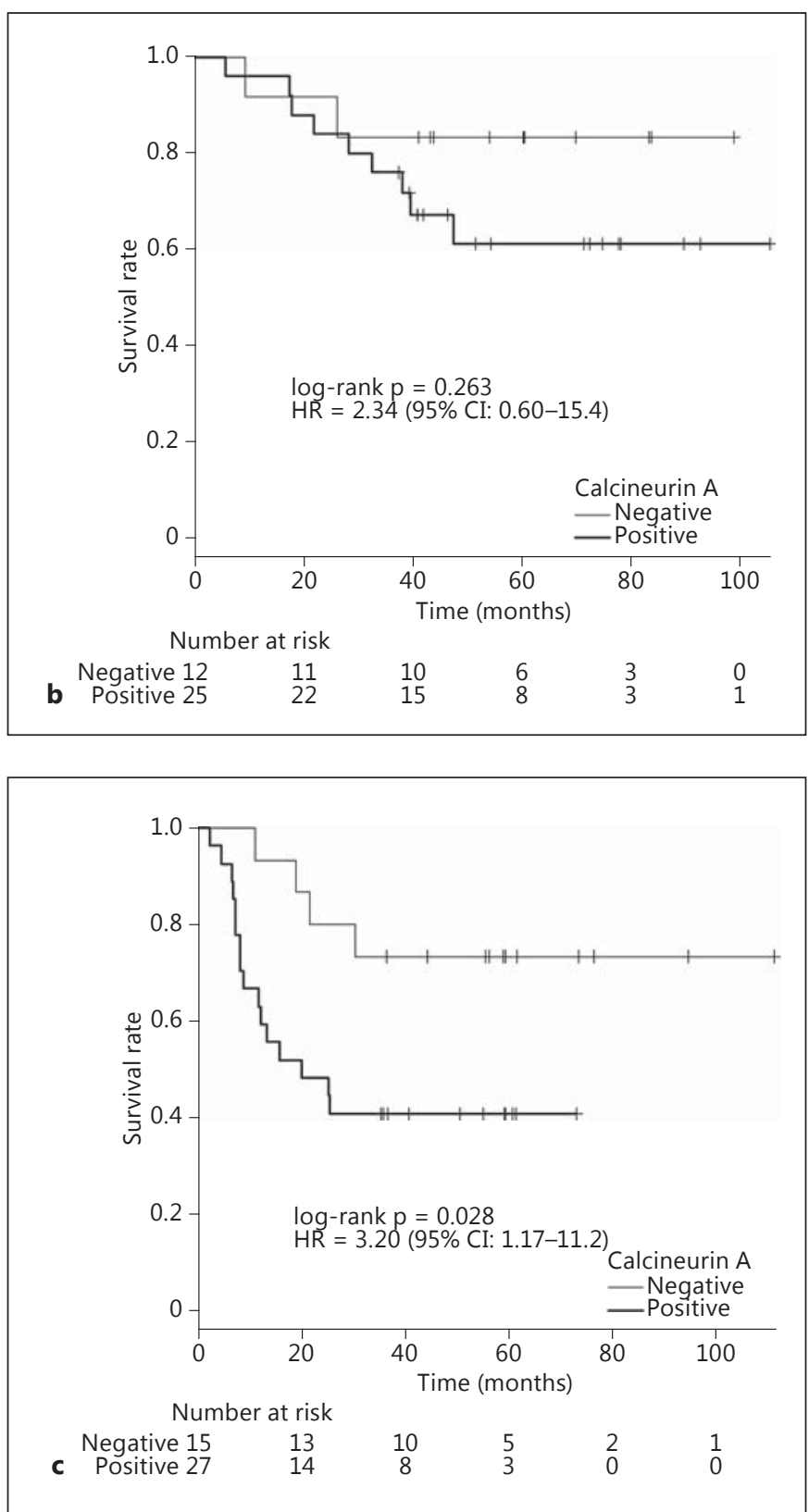

\section{Acknowledgments}

This work was supported by JSPS KAKENHI Grant-in-Aid for Scientific Research (B) grant No. 25293284 (2013-2016).

\section{Disclosure Statement}

The authors declare that they have no conflict of interest. 


\section{References}

1 Watanabe T, Itabashi M, Shimada Y, Tanaka S, Ito Y, Ajioka Y, Hamaguchi T, Hyodo I, Igarashi $M$, Ishida $H$, Ishiguro M, Kanemitsu Y, Kokudo N, Muro K, Ochiai A, Oguchi M, Ohkura Y, Saito Y, Sakai Y, Ueno H, Yoshino T, Fujimori T, Koinuma N, Morita T, Nishimura G, Sakata Y, Takahashi K, Takiuchi H, Tsuruta O, Yamaguchi T, Yoshida M, Yamaguchi N, Kotake K, Sugihara K: Japanese Society for Cancer of the Colon and Rectum (JSCCR) guidelines 2010 for the treatment of colorectal cancer. Int J Clin Oncol 2012;17:1-29.

2 Dukes CE: The classification of cancer of the rectum. J Pathol 1932;35:323-332.

3 Turnbull RB Jr, Kyle K, Watson FR, Spratt J: Cancer of the colon: the influence of the notouch isolation technic on survival rates. Ann Surg 1967;166:420-427.

4 Leslie H, Sobin MKG, Wittekind C: The TNM Classification of Malignant Tumors, ed 7. Geneva, UICC, 2009

5 Compton CC, Fielding LP, Burgart LJ, Conley B, Cooper HS, Hamilton SR, Hammond ME, Henson DE, Hutter RV, Nagle RB, Nielsen ML, Sargent DJ, Taylor CR, Welton M, Willett C: Prognostic factors in colorectal cancer. College of American Pathologists Consensus Statement 1999. Arch Pathol Lab Med 2000; 124:979-994.

6 Benson AB 3rd, Schrag D, Somerfield MR, Cohen AM, Figueredo AT, Flynn PJ, Krzyzanowska MK, Maroun J, McAllister P, Van Cutsem E, Brouwers M, Charette M, Haller DG: American Society of Clinical Oncology recommendations on adjuvant chemotherapy for stage II colon cancer. J Clin Oncol 2004; 22:3408-3419.

7 Le Voyer TE, Sigurdson ER, Hanlon AL, Mayer RJ, Macdonald JS, Catalano PJ, Haller DG: Colon cancer survival is associated with increasing number of lymph nodes analyzed: a secondary survey of Intergroup Trial INT0089. J Clin Oncol 2003;21:2912-2919.

8 Swanson RS, Compton CC, Stewart AK, Bland KI: The prognosis of T3N0 colon cancer is dependent on the number of lymph nodes examined. Ann Surg Oncol 2003;10: 65-71.

9 Ueno H, Shirouzu K, Eishi Y, Yamada K, Kusumi T, Kushima R, Ikegami M, Murata A, Okuno K, Sato T, Ajioka Y, Ochiai A, Shimazaki H, Nakamura T, Kawachi H, Kojima M, Akagi Y, Sugihara K: Characterization of perineural invasion as a component of colorectal cancer staging. Am J Surg Pathol 2013;37: 1542-1549.

10 Galizia G, Ferraraccio F, Lieto E, Orditura M, Castellano P, Imperatore V, Romano C, Vollaro M, Agostini B, Pignatelli C, De Vita F: Prognostic value of p27, p53, and vascular endothelial growth factor in Dukes A and B colon cancer patients undergoing potentially curative surgery. Dis Colon Rectum 2004;47: 1904-1914.
11 Suh KW, Kim JH, Kim YB, Kim J, Jeong S: Thymidylate synthase gene polymorphism as a prognostic factor for colon cancer. J Gastrointest Surg 2005;9:336-342.

12 Mutch MG: Molecular profiling and risk stratification of adenocarcinoma of the colon. J Surg Oncol 2007;96:693-703.

13 Astrosini C, Roeefzaad C, Dai YY, Dieckgraefe BK, Jons T, Kemmner W: REG1A expression is a prognostic marker in colorectal cancer and associated with peritoneal carcinomatosis. Int J Cancer 2008;123:409-413.

14 Ogino S, Shima K, Baba Y, Nosho K, Irahara N, Kure S, Chen L, Toyoda S, Kirkner GJ, Wang YL, Giovannucci EL, Fuchs CS: Colorectal cancer expression of peroxisome proliferator-activated receptor gamma PPARG (peroxisome proliferator-activated receptor- $\gamma$ ) is associated with good prognosis. Gastroenterology 2009; 136:1242-1250.

$15 \mathrm{Lu}$ CY, Uen YH, Tsai HL, Chuang SC, Hou MF, Wu DC, Juo SH, Lin SR, Wang JY: Molecular detection of persistent postoperative circulating tumour cells in stages II and III colon cancer patients via multiple blood sampling: prognostic significance of detection for early relapse. Br J Cancer 2011;104:11781184.

16 Mejia A, Schulz S, Hyslop T, Weinberg DS, Waldman SA: Molecular staging individualizing cancer management. J Surg Oncol 2012; 105:468-474.

17 Sinicrope FA, Shi Q, Smyrk TC, Thibodeau $\mathrm{SN}$, Dienstmann R, Guinney J, Bot BM, Tejpar S, Delorenzi M, Goldberg RM, Mahoney M, Sargent DJ, Alberts SR: Molecular markers identify subtypes of stage III colon cancer associated with patient outcomes. Gastroenterology 2015;148:88-99.

18 Madoz-Gurpide J, Canamero M, Sanchez L, Solano J, Alfonso P, Casal JI: A proteomics analysis of cell signaling alterations in colorectal cancer. Mol Cell Proteomics 2007;6:21502164.

19 Klee CB, Crouch TH, Krinks MH: Calcineurin: a calcium- and calmodulin-binding protein of the nervous system. Proc Natl Acad Sci USA 1979;76:6270-6273.

20 Klee CB, Ren H, Wang X: Regulation of the calmodulin-stimulated protein phosphatase, calcineurin. J Biol Chem 1998;273:1336713370.

21 Rusnak F, Mertz P: Calcineurin: form and function. Physiol Rev 2000;80:1483-1521.

22 Masuda ES, Imamura R, Amasaki Y, Arai K, Arai N: Signalling into the T-cell nucleus: NFAT regulation. Cell Signal 1998;10:599611.

23 Rao A, Luo C, Hogan PG: Transcription factors of the NFAT family: regulation and function. Ann Rev Immunol 1997;15:707-747.
24 Crabtree GR: Generic signals and specific outcomes: signaling through $\mathrm{Ca}^{2+}$, calcineurin, and NF-AT. Cell 1999;96:611-614.

25 Duque J, Fresno M, Iniguez MA: Expression and function of the nuclear factor of activated $\mathrm{T}$ cells in colon carcinoma cells: involvement in the regulation of cyclooxygenase-2. J Biol Chem 2005;280:8686-8693.

26 Lakshmikuttyamma A, Selvakumar P, Kanthan R, Kanthan SC, Sharma RK: Increased expression of calcineurin in human colorectal adenocarcinomas. J Cell Biochem 2005;95: 731-739.

27 Buchholz M, Schatz A, Wagner M, Michl P, Linhart T, Adler G, Gress TM, Ellenrieder V: Overexpression of c-myc in pancreatic cancer caused by ectopic activation of NFATcl and the $\mathrm{Ca}^{2+} /$ calcineurin signaling pathway. EMBO J 2006;25:3714-3724.

28 Wang YL, Wang Y, Tong L, Wei Q: Overexpression of calcineurin $\mathrm{B}$ subunit $(\mathrm{CnB})$ enhances the oncogenic potential of HEK293 cells. Cancer Sci 2008;99:1100-1108.

29 Wang S, Kang X, Cao S, Cheng H, Wang D, Geng J: Calcineurin/NFATc1 pathway contributes to cell proliferation in hepatocellular carcinoma. Dig Dis Sci 2012;57:3184-3188.

30 Manda KR, Tripathi P, Hsi AC, Ning J, Ruzinova $\mathrm{MB}$, Liapis $\mathrm{H}$, Bailey $\mathrm{M}$, Zhang $\mathrm{H}$, Maher CA, Humphrey PA, Andriole GL, Ding L, You Z, Chen F: NFATc1 promotes prostate tumorigenesis and overcomes PTEN loss-induced senescence. Oncogene DOI: 10.1038/ onc.2015.389.

31 Schmoll HJ, Twelves C, Sun W, O’Connell MJ, Cartwright T, McKenna E, Saif M, Lee S, Yothers G, Haller D: Effect of adjuvant capecitabine or fluorouracil, with or without oxaliplatin, on survival outcomes in stage III colon cancer and the effect of oxaliplatin on post-relapse survival: a pooled analysis of individual patient data from four randomised controlled trials. Lancet Oncol 2014;15:14811492.

32 Masuo T, Okamura S, Zhang Y, Mori M: Cyclosporine a inhibits colorectal cancer proliferation probably by regulating expression levels of c-Myc, p21(WAF1/CIP1) and proliferating cell nuclear antigen. Cancer Lett 2009; 285:66-72.

33 Rudraraju M, Osowo AT, Singh V, Carey EJ: Do patients need more frequent colonoscopic surveillance after liver transplantation? Transplant Proc 2008;40:1522-1524.

34 Hsiao FY, Hsu WW: Epidemiology of posttransplant malignancy in Asian renal transplant recipients: a population-based study. Int Urol Nephrol 2014;46:833-838.

35 Demir T, Ozel L, Gokce AM, Ata P, Kara M, Eris C, Ozdemir E, Titiz MI: Cancer screening of renal transplant patients undergoing longterm immunosuppressive therapy. Transplant Proc 2015;47:1413-1417. 